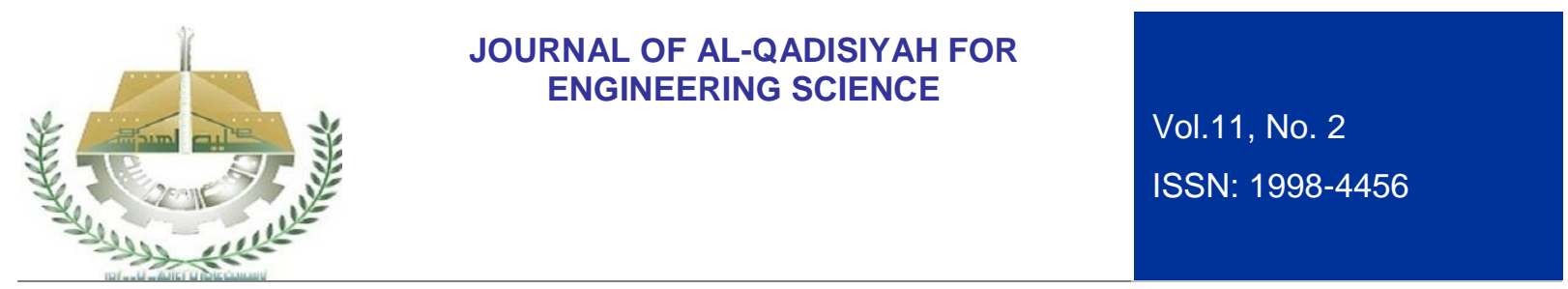

\title{
REMOVAL OF A CHEMICAL DYE FROM WASTEWATER USING LOW COST AGRO-BASED ADSORBENTS: CONTINUOUS ADSORBERS
}

\author{
Hatem Asal Gzar, \\ Assistant Prof. Dr./Civil Eng. Department/ College of Engineering/ Wasit University. \\ E mail: hatam_asal@yahoo.com \\ Noor Qassim Sabri, \\ Civil Eng. Department/ College of Engineering / Wasit University. \\ E mail:_engnoorqassim@yahoo.com
}

\begin{abstract}
Natural materials that are readily available in large amounts in nature and easily accessible may be used as low cost additives. The aim of this study is to measure the susceptibility of these locally available materials, conocarpus plant, to improve the quality of wastewater discharged from textile industry.

In addition to conocarpus- without chemically treated, conocarpus- chemically treated, carbonized conocarpus and activated carbon were used as adsorbents in order to make a comparison, and to test which one of the four types give the best efficiency for removing dye. The ability of adsorbents to adsorb dye was studied using continuous system; studied parameters were effect of flow rate, bed depth, and initial concentration. The experimental results showed that maximum removal efficiency of conocarpus - without chemically treated was found to be $90 \%$ after $75 \mathrm{~min}$ at flow rate $20 \mathrm{l} / \mathrm{h}, \mathrm{pH}$ value 3 , bed depth $5 \mathrm{~cm}$ and initial concentration $40 \mathrm{mg} / \mathrm{l}$. The maximum removal efficiency for conocarpuschemically treated was up to $83.75 \%$ after $15 \mathrm{~min}$ at flow rate $10 \mathrm{l} / \mathrm{h}, \mathrm{pH}$ value 3 , bed depth $10 \mathrm{~cm}$ and initial dye concentration $40 \mathrm{mg} / \mathrm{l}$. The maximum removal efficiency for carbonized conocarpus was up to $99.67 \%$ after $15 \mathrm{~min}$ at flow rate $10 \mathrm{l} / \mathrm{h}, \mathrm{pH}$ value 3 , bed depth $10 \mathrm{~cm}$ and initial dye concentration $40 \mathrm{mg} / \mathrm{l}$. For activated carbon the maximum removal efficiency was found to be $99.75 \%$ after $15 \mathrm{~min}$ at flow rate $10 \mathrm{l} / \mathrm{h}$, $\mathrm{pH}$ value 3 , bed depth $10 \mathrm{~cm}$ and initial dye concentration $40 \mathrm{mg} / \mathrm{l}$.
\end{abstract}

Keywords: Terasil blue dye, wastewater, treatment, low cost adsorbent, continuous study.

\section{INTRODUCTION}

The process of removing dyes and industrial wastes, is one of the major worldwide natural issues. And that textile manufacturing and dyeing is one of the processes that produce wastewater in large amounts. Wastewater-equipped textiles contain a residue treatment bath from preparation,dyeing, finishing, reduction, and other processes (Korbahti 2007).

Wastes from textile and dyeing industry cause serious environmental damage to adjacent aquatic particle because of presence of hazardous chemical dyes, dark coloring and chlorine residues (Asamudo et al., 2005 ; Senel et al., 2012). 


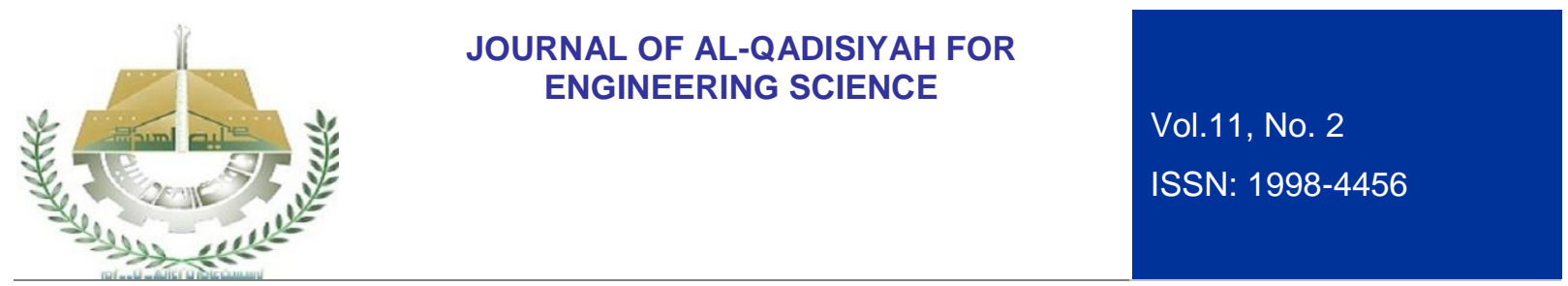

Many chemical, physical and biological processes have been used, such as image oxidation and adsorption processes, to remove the chemical dyes used in the dyeing process. At all times, The adsorption process is used to collect chemical dyes on a solid matrix before biological and chemical treatments (Ozmihci and Kargi, 2006; Aydın et al., 2007).

One of the materials used as a adsorbent is activated carbon powder although its high price but is the most effective material used to remove organic compounds because of large area $\left(1000 \mathrm{~m}^{2} \mathrm{G}^{-1}\right)$ and its high ability to absorb (Karthikeyan and Mohan, 1997; Kestioglu and Yalili, 2006; Ozer and Akdemir, 2013) .

many kinds have been studied of agricultural crops to dispose of dye from sewage Like mud produced by the sugar industry (Magdy and Deifullah, 1998), rice husk (Mackay et al., 1986), peel of orange ( Namasivayam et al., 1996) and other agricultural crops like wood (Mackay et al., 1998), Cassava peels and Kenaf (Hussein et al., 2016)

In this study, Conocarpus plant was used as absorbent material to remove the terasil dye from Kut textile plant, it is have fast growing and available in large quantities and easy to obtain.

\section{EXPERIMENTAL PROCEDURE AND METHODS}

\subsection{SOURCE OF WASTEWATER}

Solution was prepared by dissolving (40) $\mathrm{mg}$ of terasil blue dye in $1000 \mathrm{ml}$ of a tap water, this concentrations of solution will be used for all experiments. The dye components (Table 1) were examined using Eds device (Type X - act , USA). The measurements were conducted at the Central Service Laboratory - College of Education Ibn Alhaitham, University of Baghdad.

Table 1. the components in terasil blue dye

\begin{tabular}{|l|l|l|}
\hline Element & Weight\% & Atomic\% \\
\hline $\mathrm{C}$ & 37.45 & 50.29 \\
\hline $\mathrm{O}$ & 35.52 & 35.81 \\
\hline $\mathrm{Na}$ & 9.89 & 6.94 \\
\hline $\mathrm{S}$ & 8.52 & 4.29 \\
\hline $\mathrm{Cl}$ & 3.72 & 1.69 \\
\hline $\mathrm{Br}$ & 4.90 & 0.99 \\
\hline Totals & 100 & 100 \\
\hline
\end{tabular}

\subsection{ADSORBENTS}

In this study, four absorbent substances were used conocarpus-without chemically treated, carbonized conocarpus, conocarpus - after chemically treated, and activated carbon.

\subsection{PHYSICAL PROPERTIES OF ADSORBENTS}

Physical properties of conocarpus plant, carbonized conocarpus and activated carbon have been measured such as solubility, specific surface area, bed porosity, bulk density, real density, pore volume and pore size. The measurements were conducted at Ministry of Oil / Petroleum Research \& Development Center, 


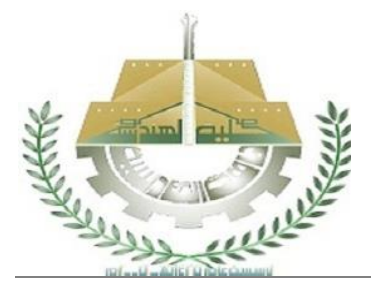

JOURNAL OF AL-QADISIYAH FOR

ENGINEERING SCIENCE

Baghdad. Physical properties of the conocarpus, carbonized conocarpus and activated carbon are illustrated in table (2) .

Table 2. Physical properties of adsorbent materials: conocarpus, carbonized conocarpus and activated carbon.

\begin{tabular}{|l|c|c|c|}
\hline \multicolumn{1}{|c|}{ Properties } & Conocarpus & $\begin{array}{c}\text { Carbonized } \\
\text { conocarpus }\end{array}$ & Activated carbon \\
\hline Color & Green & Black & Black \\
\hline Appearance & Powder & Powder & Powder \\
\hline Odors & Odor & Odorless & Odorless \\
\hline Solubility & Insoluble in Water & Insoluble in Water & Insoluble in Water \\
\hline $\begin{array}{l}\text { SpecificSurface } \\
\text { Area }\left(\mathrm{m}^{2} / \mathrm{g}\right)\end{array}$ & 0.1217 & 83.387 & 732.6352 \\
\hline Bed Porosity & & & \\
\hline Bulk Density $\left(\mathrm{g} / \mathrm{cm}^{3}\right)$ & 0.526669 & 0.822401 & 0.815945 \\
\hline Real Density $\left(\mathrm{g} / \mathrm{cm}^{3}\right)$ & 0.7117 & 0.3723 & 0.4123 \\
\hline Pore volume $\left(\mathrm{cm}^{3} / \mathrm{g}\right)$ & 1.5036 & 2.0963 & 2.2401 \\
\hline Pore Size $(\mathrm{nm})$ & 0.000542 & 0.078202 & 0.540373 \\
\hline
\end{tabular}

\subsection{CHARACTERIZATION OF ADSORBENTS}

Figures (1), (2) and (3) show the outer surface and surface morphology of the conocarpus, carbonized conocarpus and activated carbon particles respectively using scanning electron microscope SEM (Type AIS2300, USA). The measurements were conducted at the Central Service Laboratory - College of Education Ibn Alhaitham, University of Baghdad.

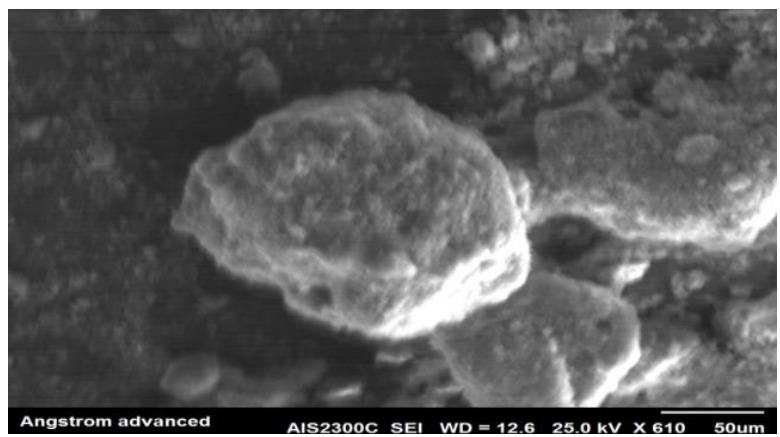

Figure 1. SEM micrograph of conocarpus. 

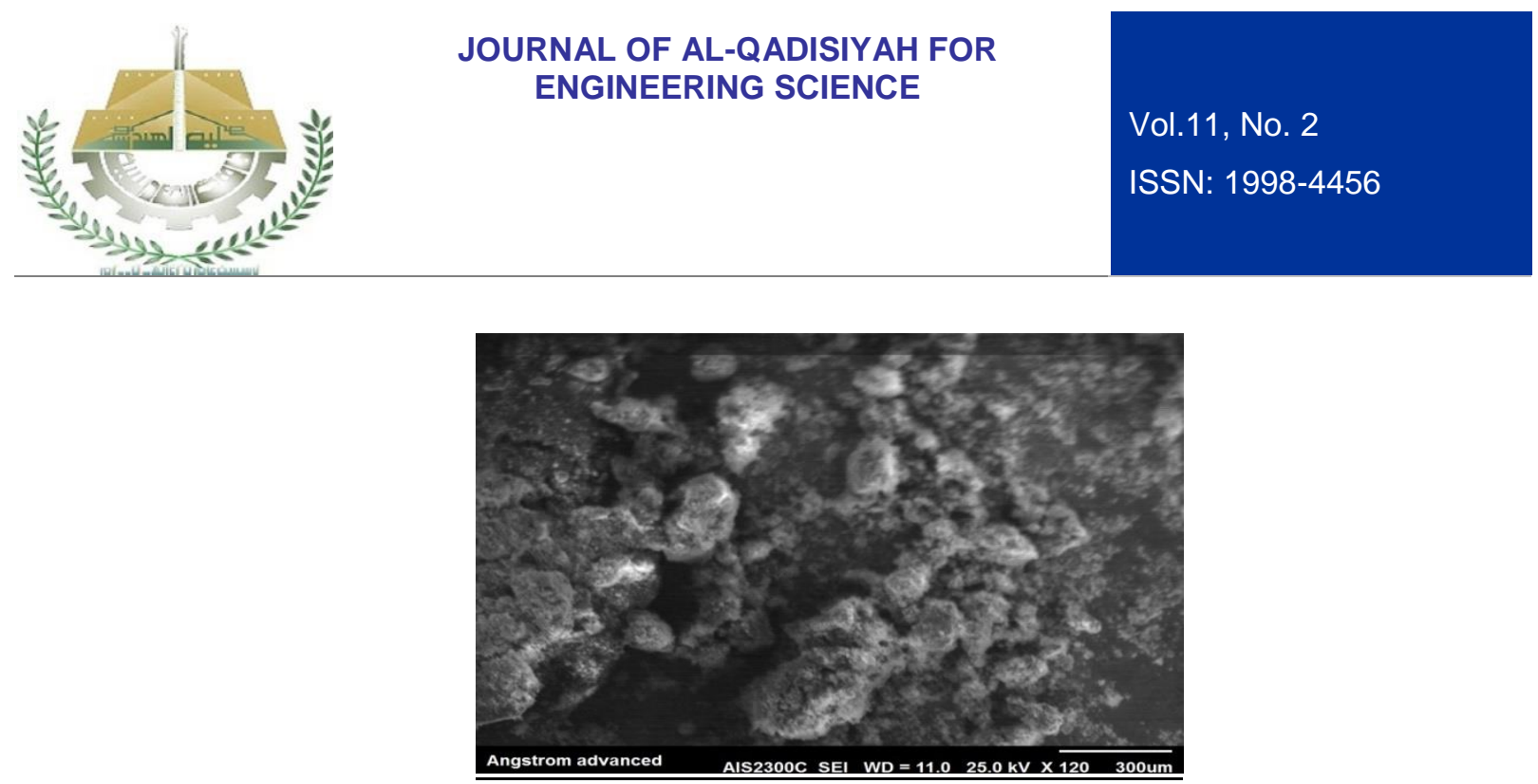

Figure 2. SEM micrograph of carbonized conocarpus.

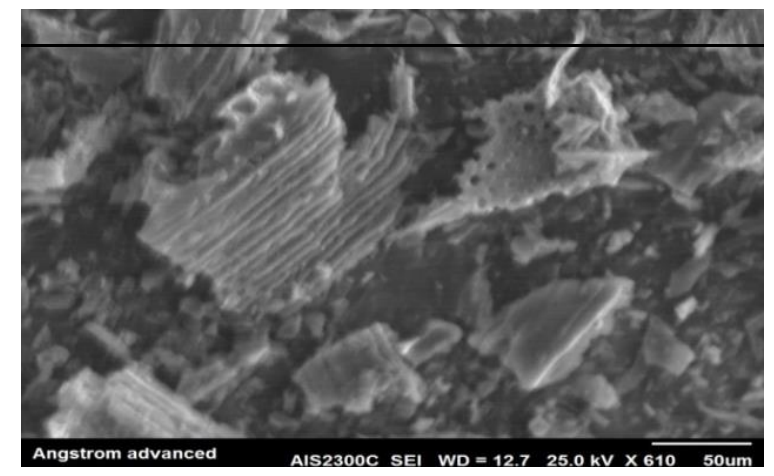

Figure 3. SEM micrograph of activated carbon.

\subsection{PREPARATION OF THE ADSORBENTS}

Preparation of the adsorbent materials; conocarpus -without chemically treated, conocarpus-after chemically treated and carbonized conocarpus are illustrated below.

\subsubsection{Preparation of conocarpus-without chemically treated}

Conocarpus leaves was taken from the campus of Wasit University to be used in this study. The previous studies (Hussein et al., 2016) were adopted as a working method for preparation of conocarpus. Plant leaves washed three times by using distilled water to get rid of any dust. After finishing washing, it is dried in the oven at $110^{\circ} \mathrm{C}$ for 3 hours; then grinded in a mill to a small volume of less than 500 microns. The last step of the preparation process is sieving through $(150-300) \mu \mathrm{m}$. Figure (4) shows the Preparation of conocarpus adsorbent. 

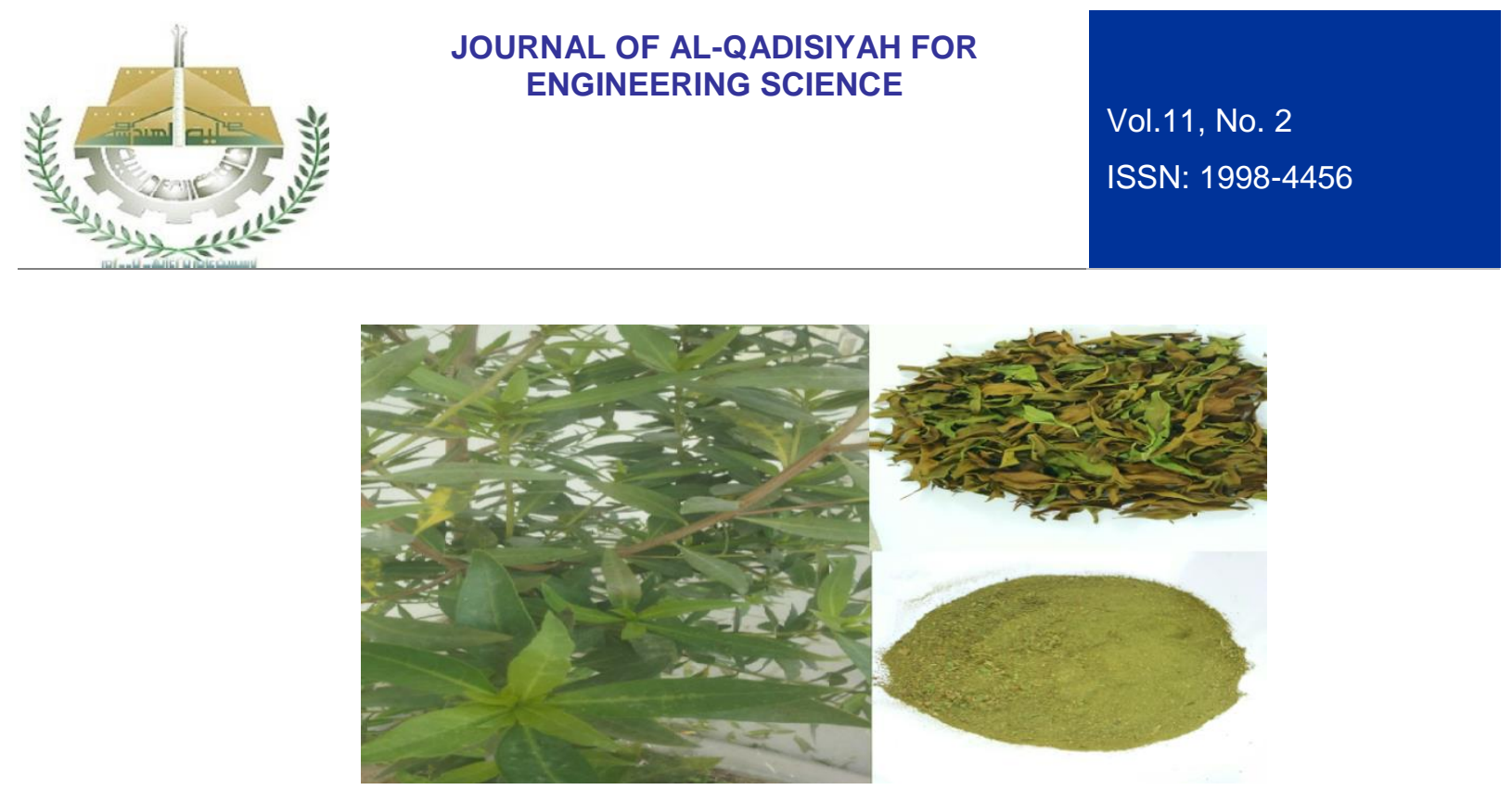

Figure 4. Preparation of conocarpus adsorbent.

\subsubsection{Preparation of carbonized conocarpus}

The previous studies (Ramadan et al., 2005) were adopted as a working method for carbonization of conocarpus plants. The following steps illustrate the preparation of carbonized conocarpus:

1. Cutting the plant into small pieces.

2. Washing it three times with distilled water to clean it.

3. Dry it at $110{ }^{\circ} \mathrm{C}$ for three hours and repeat the drying step for other quantities until the required quantity is obtained.

4. The dried plant is grinded into small granules using grinder.

5. 1: 0.5 of the conocarpus and sodium hydroxide are mixed well.

6. Put the mixture in oven at temperature $300 \mathrm{oC}$ for half an hour with continuous flipping

7. Raise the temperature to $500{ }^{\circ} \mathrm{C}$ for an hour and a half. The total time for carbonization process was two hours.

8. Wash the product in the filtration device twice with distilled water and then washed with hydrochloric acid at a concentration of $10 \%$ once to remove the effect of base solution then wash it with water once to remove acidic excitation.

9. The product is then dried in oven at $110^{\circ} \mathrm{C}$ for three hours, then grinded into small granules.

10. Sieving the product through $(150-300 \mu \mathrm{m})$.

Conocarpus, carbonized conocarpus, after preparation are shown in figure (5) 


\section{JOURNAL OF AL-QADISIYAH FOR ENGINEERING SCIENCE}

conocarpus-without Carbonized conocarpus chemically treated

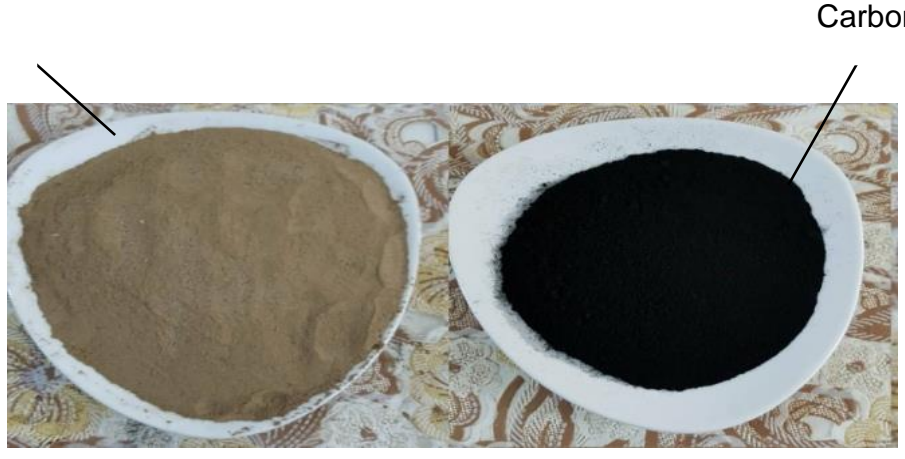

Figure 5. conocarpus-without chemically treated and carbonized conocarpus, materials used as adsorbents in the present study.

\subsubsection{Preparation of conocarpus- chemically treated}

Several experiments were conducted to pull the color of the conocarpus. The best result was obtained using the following procedure:

1. Cutting plant leaves.

2. Washed three times with distilled water to get rid of any dust.

3. Dried in the oven at $110^{\circ} \mathrm{C}$ for 3 hours.

4. Grinded in a mill to a small volume of less than 500 microns.

5. Wash the product again in the filtration device twice with distilled water.

6. Put the product in solution of hydrochloric acid at a concentration of $10 \%$ For a full day then wash it with water once to remove acidic excitation.

7. Wash the product again in the filtration device with Hydrogen peroxide then wash it with water once to remove Hydrogen peroxide excitation.

8. Dried in the oven at $110^{\circ} \mathrm{C}$ for 3 hours.

9. Grinded in a mill to a small volume of less than 500 microns.

10. The last step of the preparation process is sieving through (150 -300) $\mu \mathrm{m}$. Figure (6) shows conocarpus- after Chemically treated. 


\subsection{ACTIVATED CARBON}

Powder activated carbon PAC (German origin) as shown in figure(7) was used as adsorbent in the experiments. PAC Specifications are shown in table (3).

Table 3. Specifications of activated carbon.

\begin{tabular}{|l|l|}
\hline Specification & Value \\
\hline $\mathrm{MW}$ & $12.01 \mathrm{~g} / \mathrm{mol}$ \\
\hline Soluble in water & $<0.2 \%$ \\
\hline Soluble in $\mathrm{HCL}$ & $<1 \%$ \\
\hline Soluble in $\mathrm{C}_{2} \mathrm{H}_{5} \mathrm{OH}$ & $<0.2 \%$ \\
\hline Chloride $\mathrm{Cl}$ & $<0.001 \%$ \\
\hline Cooper $\mathrm{Cu}$ & $<0.05 \%$ \\
\hline Iron $\mathrm{Fe}$ & $<0.002 \%$ \\
\hline Lead $\mathrm{Pb}$ & $<0.001 \%$ \\
\hline & \\
\hline
\end{tabular}




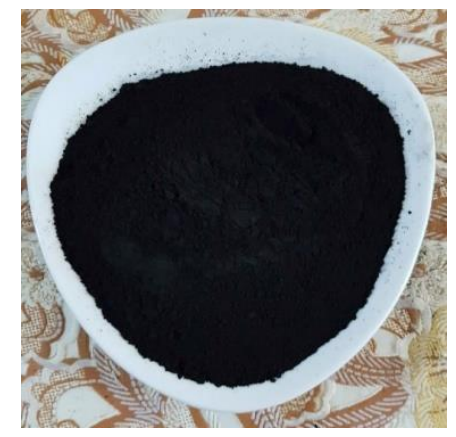

Figure 7. Activated carbon

\subsection{EXPERIMENTAL WORK}

The schematic equipment for experimental representation is shown in Figure (8).

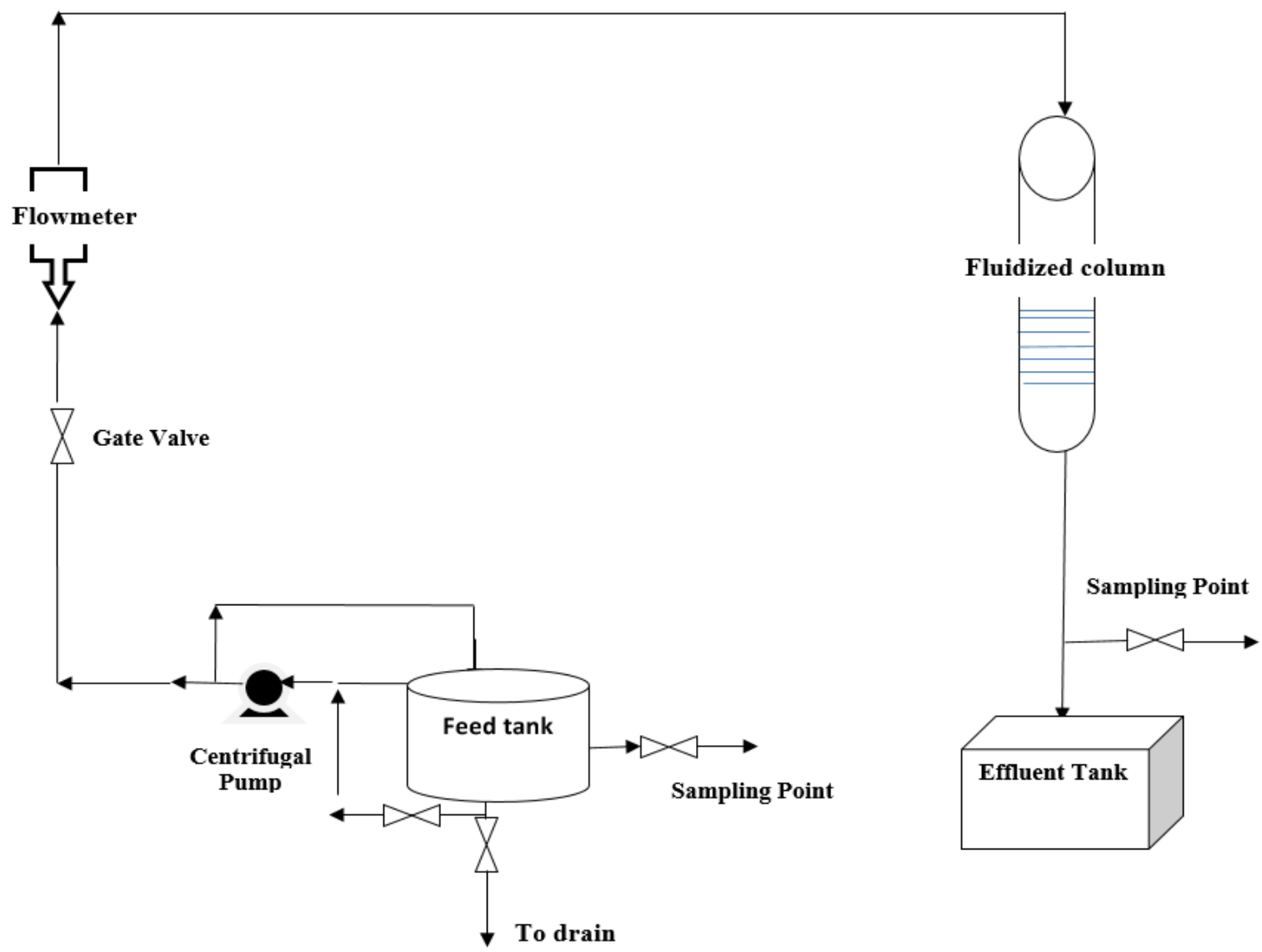

\subsection{SYSTEM STRUCTURE AND EQUIPMENT REQUIREMENTS}

a. 80-liter cylindrical steel tank for preparation of terasil blue dye solution. 
b. 30 liter container for liquid waste collection.

c. column made of glass material with an internal diameter of $50 \mathrm{~mm}$ and height of 1000 .

d. PVC flanges and various sizes of hoses and pipes joined together by different fittings.

e. Flow meter to measure flow rate $(0-30 \mathrm{l} / \mathrm{h})$.

f. Pump of maximum capacity of 50 liters / hour.

g. Gate valves are used to control the flow in the system.

h. Two sampling points were selected, first from the top of the fluidized column and the other before the feeding tank.

\subsection{EXPERIMENTAL PROCEDURE}

a - The adsorbent was placed in adsorption column to the required bed depth.

b-The terasil blue dye solution with the desired concentration was prepared in the cylindrical steel tank, using tap water.

c- The terasil blue dye solution was adjusted to $\mathrm{pH} 3$ using $\mathrm{NaOH}$ or $\mathrm{HCl}$.

d- The terasil dye solution was pumped into the absorption column through the flow meter at the required flow rate.

e- Samples were taken periodically; the concentration of terasil dye was measured using UV device (type IRPRESTIGE-2; Shimadzu 8000, Japan).

$f-$ The break through curves were determined by plotting $\left(\mathrm{C}_{\mathrm{e}} / \mathrm{C}_{0}\right)$ with time. The experimental conditions are shown in table (4).

Table 4. Experimental conditions of the experiments used in the present study.

\begin{tabular}{|c|c|}
\hline Adsorbents & $\begin{array}{l}\text { conocarpus-without chemically treated } \\
\text { conocarpus- chemically treated } \\
\text {,carbonized conocarpus and activated } \\
\text { carbon }\end{array}$ \\
\hline Adsorbate & Terasil \\
\hline Bed Depth, cm & $5,7.5,10$ \\
\hline Flow rate, $(\mathrm{l} / \mathrm{h})$ & $3,10,20$ \\
\hline Initial Concentration $(\mathrm{mg} / \mathrm{l})$ & $40,70,140$ \\
\hline 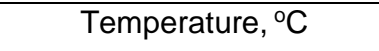 & $20^{\circ} \mathrm{C} \pm 1$ \\
\hline Particle size, $\mathrm{mm}$ & $(150-300)$ micron \\
\hline $\mathrm{pH}$ & 3 \\
\hline
\end{tabular}

\section{RESULTS AND DISCUSSION}




\subsection{EFFECT OF FLOW RATE}

The effect of flow rate on the adsorption process in fluidized bed column was investigated. Breakthrough curves were obtained at different flow rates 3,10 , and $20 \mathrm{l} / \mathrm{h}$ at initial concentration $40 \mathrm{mg} / \mathrm{l}$ and bed depth 5 $\mathrm{cm}$, as shown in figures (9), (10) and (11).

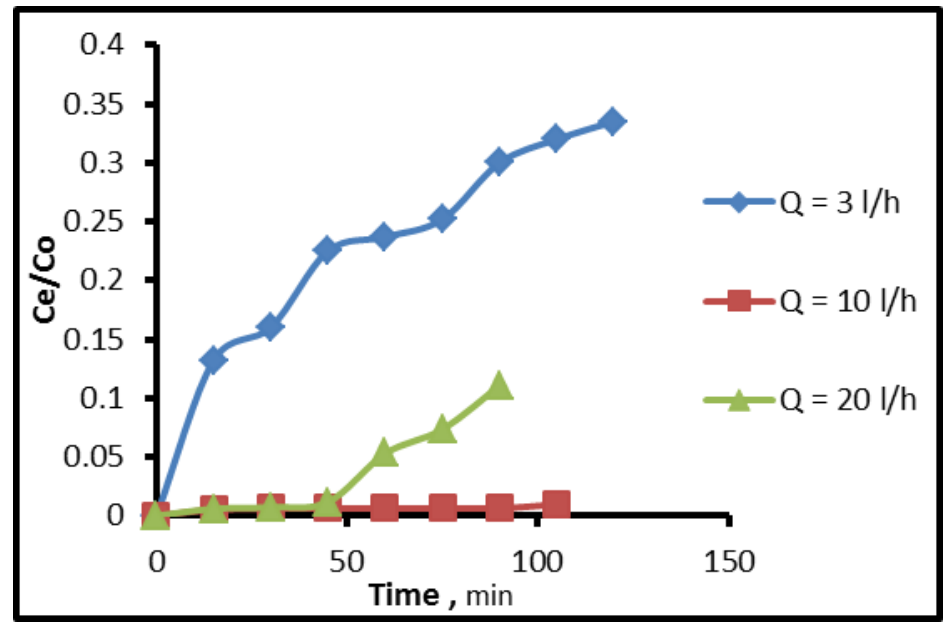

Figure 9. Breakthrough curves for terasil dye adsorption onto activated carbon at different flow rates, $20^{\circ} \mathrm{C}$, and $\mathrm{pH} 3$.

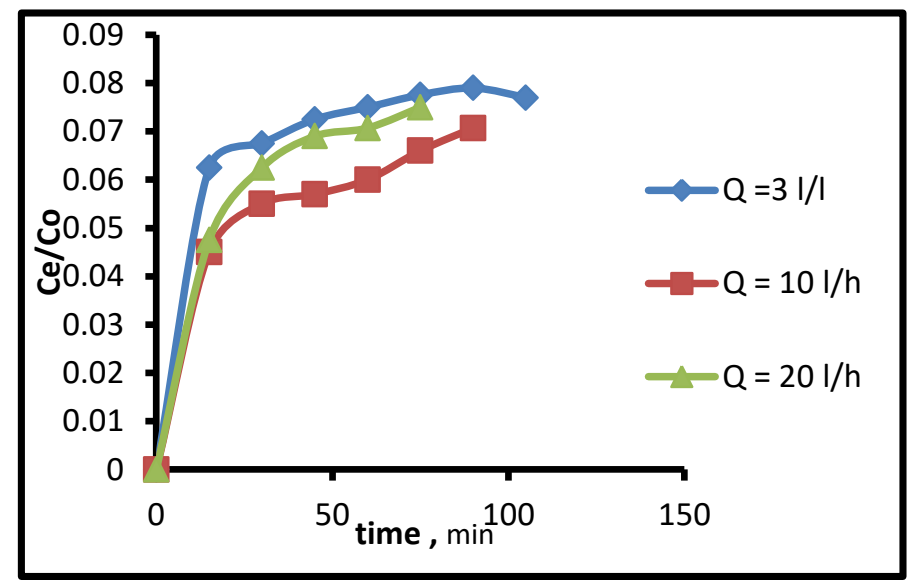

Figure 10. Breakthrough curves for terasil dye adsorption onto carbonized conocarpus at different flow rates, $20^{\circ} \mathrm{C}$, and $\mathrm{pH} 3$ 

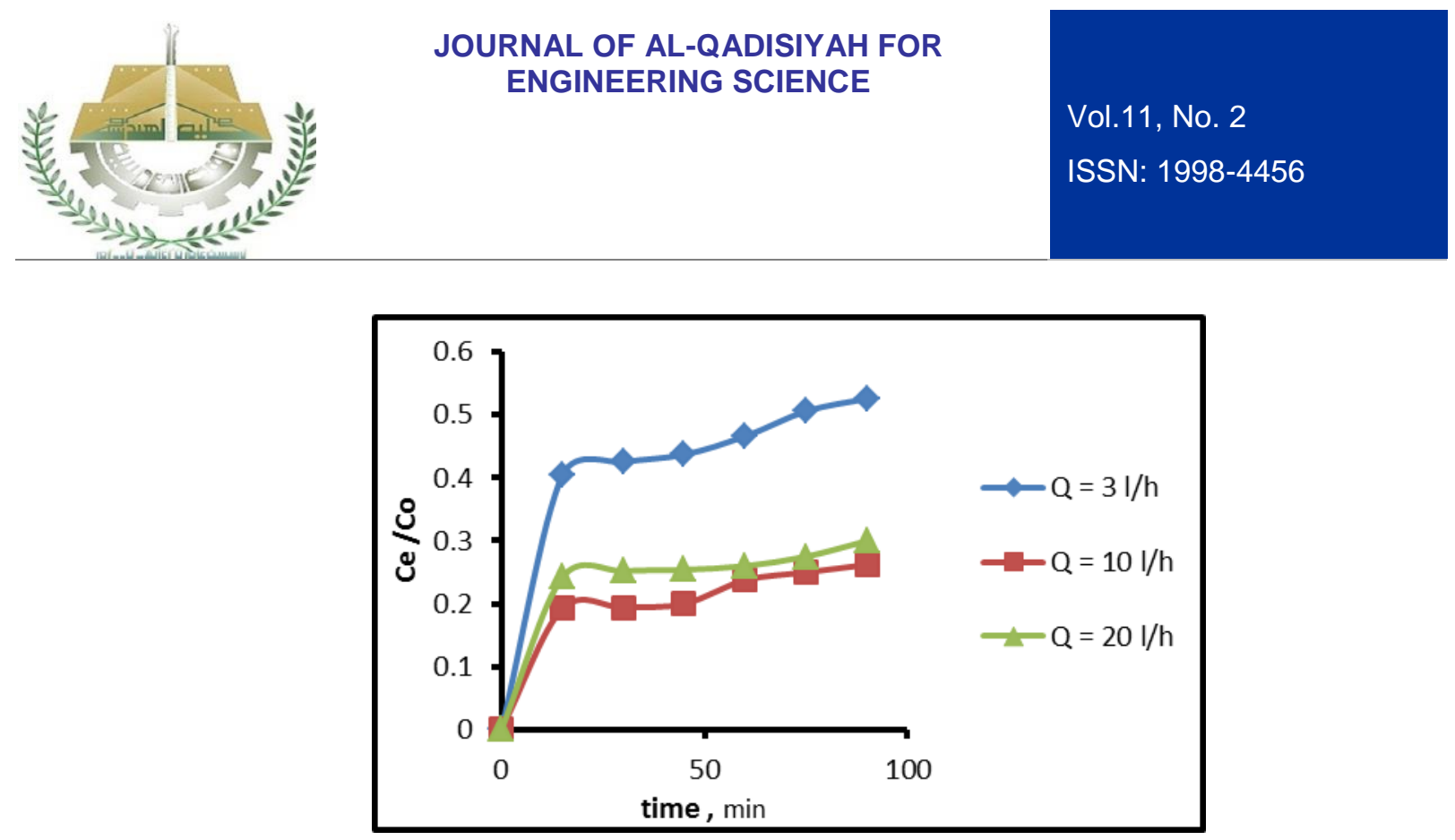

Figure 11. Breakthrough curves for terasil dye adsorption onto conocarpus - after chemically treated at different flow rates, $20^{\circ} \mathrm{C}$, and $\mathrm{pH} 3$.

When the adsorbent; activated carbon, carbonized conocarpus and conocarpus - after chemically treated; were used at flow rates $10 \mathrm{l} / \mathrm{h}$ and $20 \mathrm{l} / \mathrm{h}$, the breakthrough curves occurred rapidly with increasing flow rate because the dye had less time to contact with absorbent materials that led to the removal of less dye figures (9), (10) and (11). The breakthrough period increased significantly with a decrease in flow. Absorption becomes smaller with increased hydraulic load due to reduced contact time between dye and absorbent materials. With high flow rate, Ce /Co increase rapidly. Compared to a fixed bed column it did not have this speed because the surface area of the absorbent material is limited in the fixed bed due to the dead zone that appear between the particles. These results are consistent with the results obtained by Wang et al., (1997).

At low flow rate $3 \mathrm{l} / \mathrm{h}$ the dispersion velocity of the absorbent materials and dye is low, so their kinetic energy becomes less and the attractiveness of the dye molecules decreases. Therefore, the adsorption process is less efficient when discharge is very low.

When the concarpus-without chemically treated was used as adsorbent, a quick absorption of the terasil blue dye occurred as the flow rate decrease (figure 12). The breakthrough curves have reached a breakthrough state with remarkable speed at low flow rate. This is because the low flow rate the greater contact time for the solution with sorbent, and the more time lead to the plant's susceptibility to give the green color, because of the plant did not undergo to carbonization process or chemically treated.

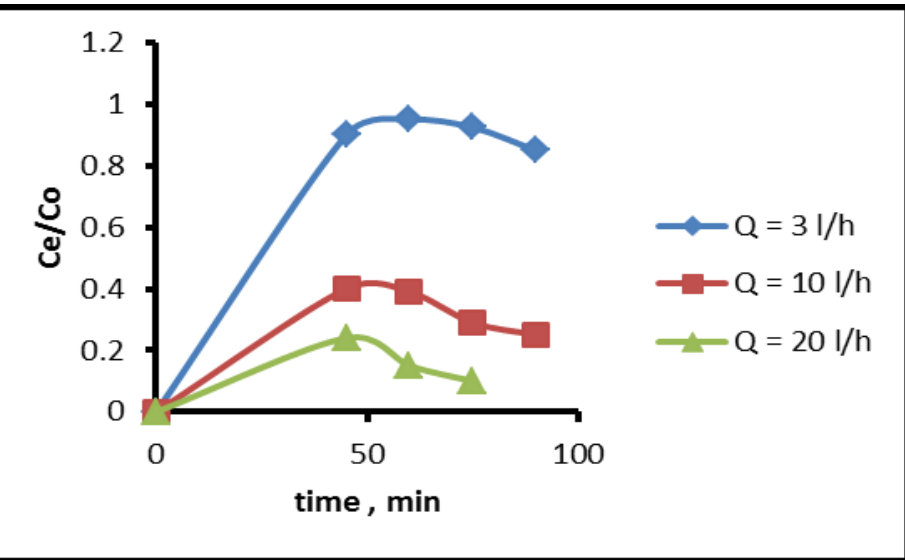

Figure 12. Breakthrough curves for terasil dye adsorption onto conocarpus- without chemically treated at different flow rates, $20^{\circ} \mathrm{C}$, and $\mathrm{pH} 3$ 


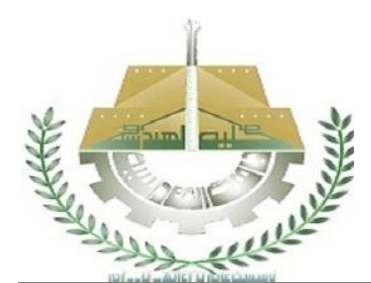

JOURNAL OF AL-QADISIYAH FOR ENGINEERING SCIENCE

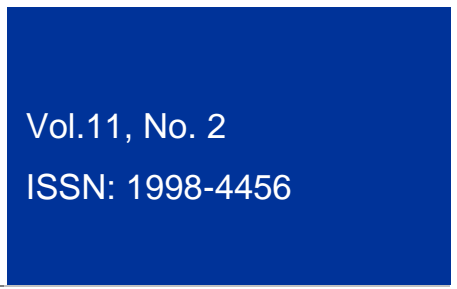

By comparing the three adsorbent to investigate the effect of the flow rate $3 \mathrm{I} / \mathrm{h}$ on the adsorption process, it is shown that carbonized conocarpus is more effective in the process of adsorption where the maximum efficiency of removal $93.75 \%$, followed by activated carbon where the maximum efficiency of removal 86,75 $\%$. For the conocarpus - after chemically treated, the maximum efficiency of removal was $59.6 \%$, and for the conocarpus-without chemically treated the maximum efficiency of removal was $25 \%$.

At flow rate $10 \mathrm{l} / \mathrm{h}$, it is shown that activated carbon is more effective in the process of adsorption where the maximum efficiency of removal $99.44 \%$, followed by carbonized conocarpus where the maximum efficiency of removal $95.45 \%$. For the conocarpus - after chemically treated the maximum efficiency of removal was $80.72 \%$ and for the conocarpus -without chemically treated the maximum efficiency of removal was $75 \%$.

At flow rate $20 \mathrm{l} / \mathrm{h}$, it is shown that activated carbon is more effective in the process of adsorption where the maximum efficiency of removal $99.4 \%$, followed by carbonized conocarpus where the maximum efficiency of removal $95.25 \%$, for the conocarpus -without chemically treated the maximum efficiency of removal was $90 \%$, and for the conocarpus - after chemically treated the maximum efficiency of removal was $75.77 \%$.

\subsection{EFFECT OF BED DEPTH}

From figures (13) , (14) and (15) the slope of the breakthrough curve at a bed depth of $10 \mathrm{~cm}$ is lower than that of $7.5 \mathrm{~cm}$ and $5 \mathrm{~cm}$. When the bed depth increases, the removal efficiency increases. In the higher depth, more terasil dye pull out from the solution compared to the lower depth. It also shown that the curved slope of breakthrough curves less in fluidized bed compared to a fixed bed because of the presence of dead zone that appear in the hard bed. These conclusions are similar to those obtained by Han et al, (2006).

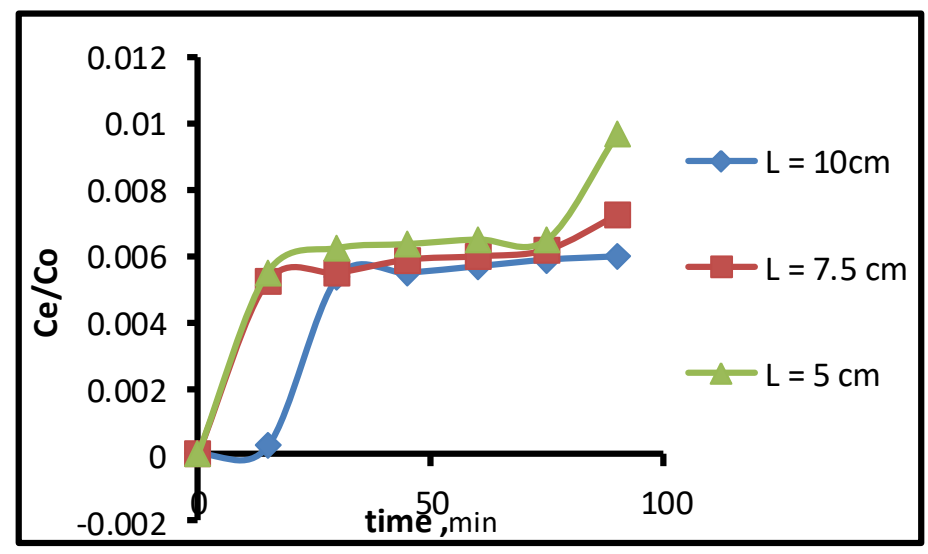

Figure 13. Breakthrough curves for terasil dye adsorption onto activated carbon, at different bed depths,

$20^{\circ} \mathrm{C}$, and $\mathrm{pH} 3$. 


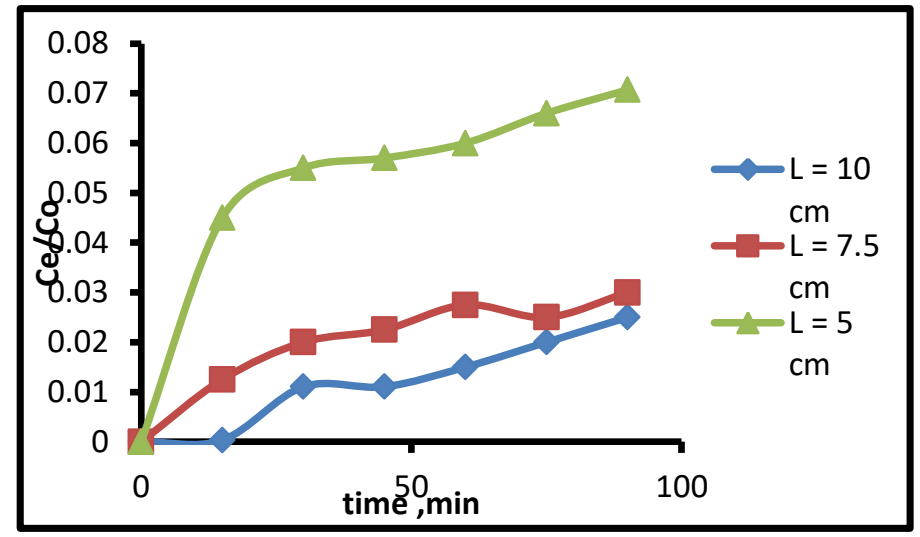

Figure 14. Breakthrough curves for terasil dye adsorption onto carbonized conocarpus, at different bed depths, $20^{\circ} \mathrm{C}$, and $\mathrm{pH} 3$.

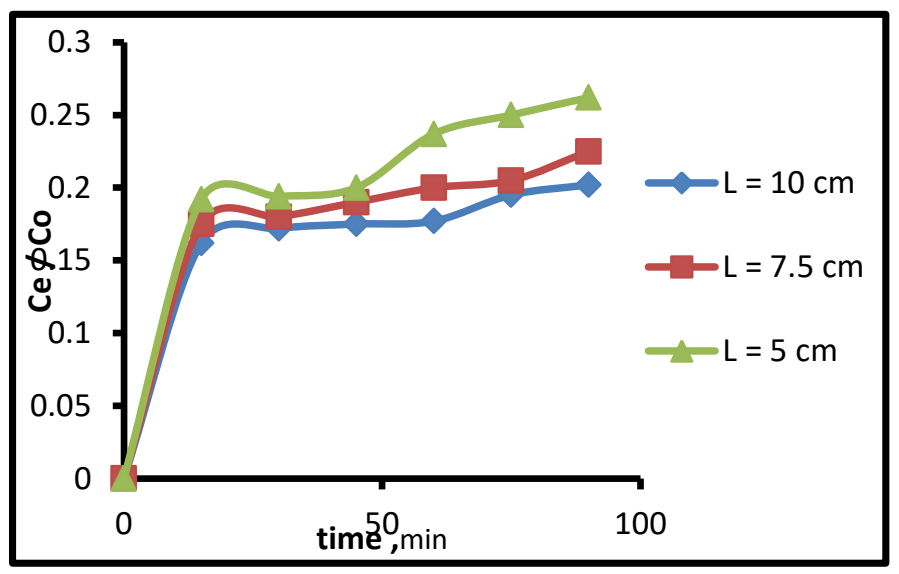

Figure 15. Breakthrough curves for terasil dye adsorption onto conocarpus - after chemically treated, at different bed depths, $20^{\circ} \mathrm{C}$, and $\mathrm{pH} 3$.

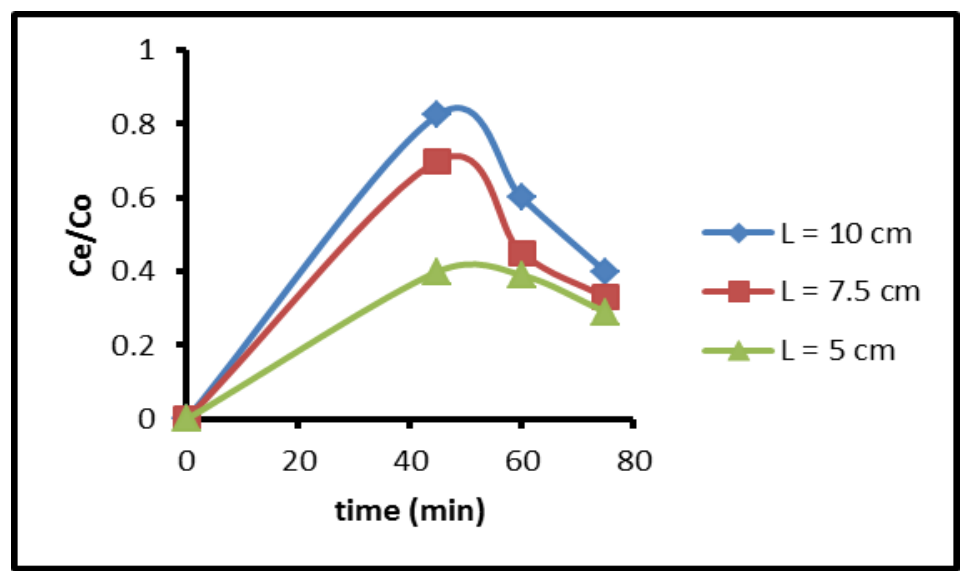

Figure 16. Breakthrough curves for terasil dye adsorption onto conocarpus-without chemically treated, at different bed depths, $20^{\circ} \mathrm{C}$, and $\mathrm{pH} 3$. 


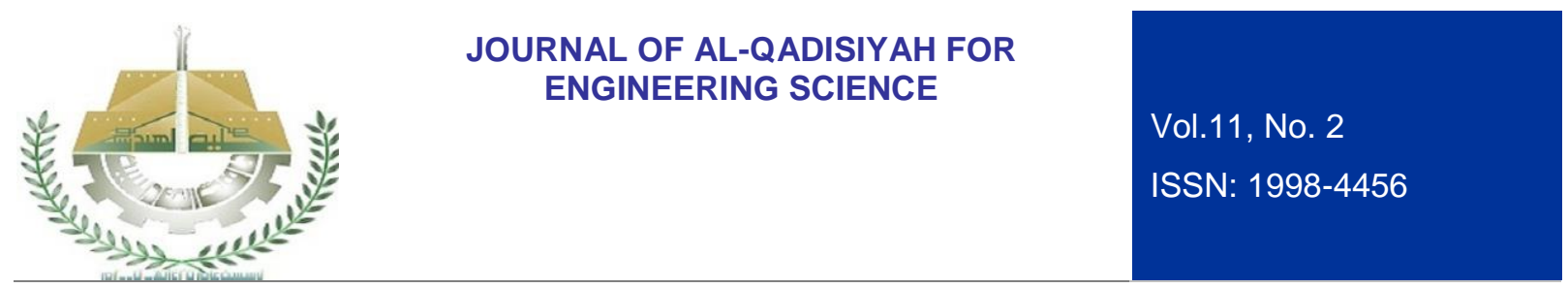

From figure (16) when the bed depth increases the effectiveness of a adsorption process decreases, because of increasing the ability of conocarpus plant to give the color.

By comparing among the adsorbents, the effect of the bed depth on the efficiency of the adsorption process was investigated. At $10 \mathrm{~cm}$ depth it is shown that activated carbon and carbonized conocarpus were more effective in the process of adsorption where the efficiency of removal $99.75 \%$ and $99.67 \%$, respectively. While the maximum removal of efficiency of conocarpus-after chemically treated was $83.75 \%$, and the maximum removal of efficiency of conocarpus was $60 \%$.

At the bed depth $7.5 \mathrm{~cm}$, it is shown that activated carbon is more effective in the process of adsorption where the maximum efficiency of removal $99.48 \%$, followed by carbonized conocarpus where the maximum efficiency of removal $98.75 \%$, While the maximum removal of efficiency of conocarpus - after chemically treated was $82.25 \%$, and for the conocarpus plant the maximum efficiency of removal was $67 \%$.

At bed depth $5 \mathrm{~cm}$, it is shown that activated carbon is more effective in the process of adsorption where the maximum efficiency of removal $99.44 \%$, followed by carbonized conocarpus where the maximum efficiency of removal $95.45 \%$. While the maximum removal of efficiency of conocarpus - after chemically treated was $80.72 \%$, and for the conocarpus plant the maximum efficiency of removal was $75 \%$.

\subsection{EFFECT OF INITIAL CONCENTRATION}

Figures (17) to (20) show the effect of initial concentration of dye on the shape of breakthrough curves. Three initial concentrations 40,70 and $140 \mathrm{mg} / \mathrm{L}$ were adopted in the fluidized bed column experiments. Whenever the initial concentration increases, the more likely the penetration curves are obtained. At the highest initial concentration of terasil blue dye, the absorbent bed is exhausted in the shortest time and this leads to early breakthrough. This has a decrease in the stop point with increased concentration of the dye where the link sites are quickly saturated in the column. The curved slope of breakthrough curves less in fluidized bed compared to a fixed bed because of the presence of dead zone in fixed bed.

By comparing among the adsorbents, at initial concentration $40 \mathrm{mg} / \mathrm{L}$, it is shown that activated carbon is more effective in the process of adsorption where the maximum efficiency of removal $99.44 \%$, followed by carbonized conocarpus where the maximum efficiency of removal $95.45 \%$. While the maximum removal of efficiency of conocarpus - after chemically treated was $80.72 \%$, and for the conocarpus the maximum efficiency of removal was $75 \%$.

At initial concentration of terasil dye $70 \mathrm{mg} / \mathrm{L}$, it is shown that activated carbon is more effective in the process of adsorption where the maximum efficiency of removal $94.14 \%$, followed by carbonized conocarpus plant where the maximum efficiency of removal $93 \%$. While the maximum removal of efficiency of conocarpus - after chemically treated was $71.42 \%$, and for the conocarpus plant the maximum efficiency of removal was $21.4 \%$.

At initial concentration of terasil dye of $140 \mathrm{mg} / \mathrm{L}$, it is shown that activated carbon is more effective in the process of adsorption where the maximum efficiency of removal $89.28 \%$, followed by carbonizedconocarpus where the maximum efficiency of removal $82.14 \%$. While the maximum removal of efficiency of conocarpus - after chemically treated was $65 \%$, and for the conocarpus plant the maximum efficiency of removal was $13 \%$. 


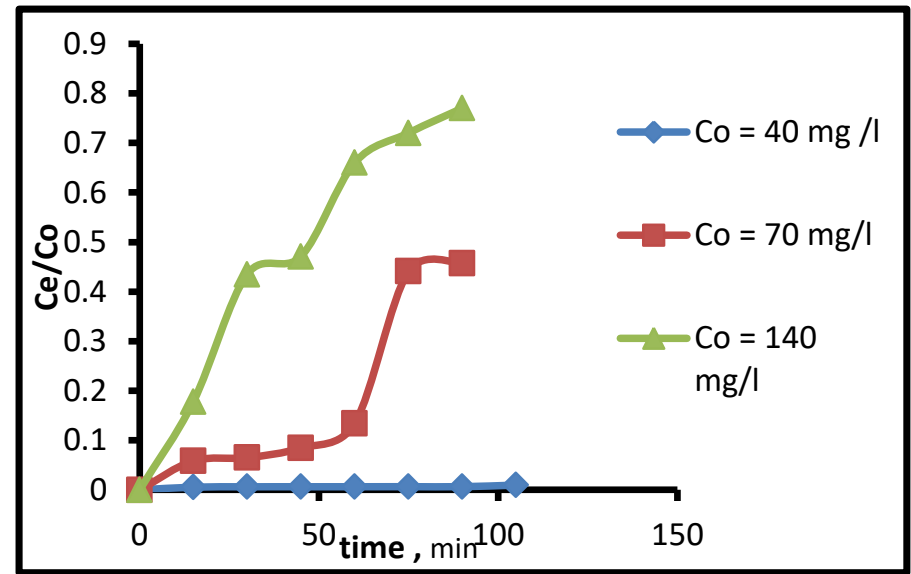

Figure 17. Breakthrough curves for dye biosorption onto activated carbon, at different initial concentrations, $20^{\circ} \mathrm{C}$, and $\mathrm{pH} 3$.

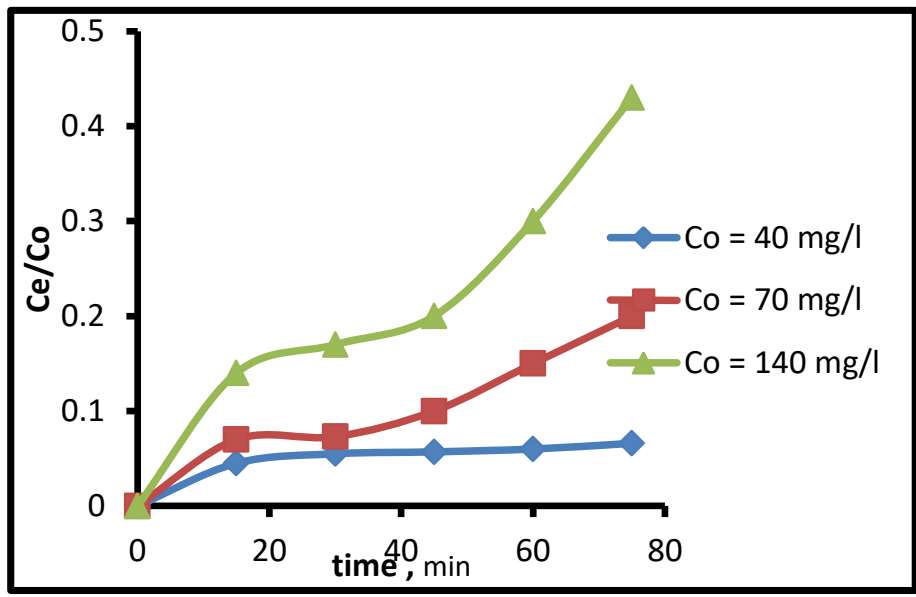

Figure 18. Breakthrough curves for terasil dye adosorption onto carbonized conocarpus, at different initial concentrations, $20^{\circ} \mathrm{C}$, and $\mathrm{pH} 3$. 

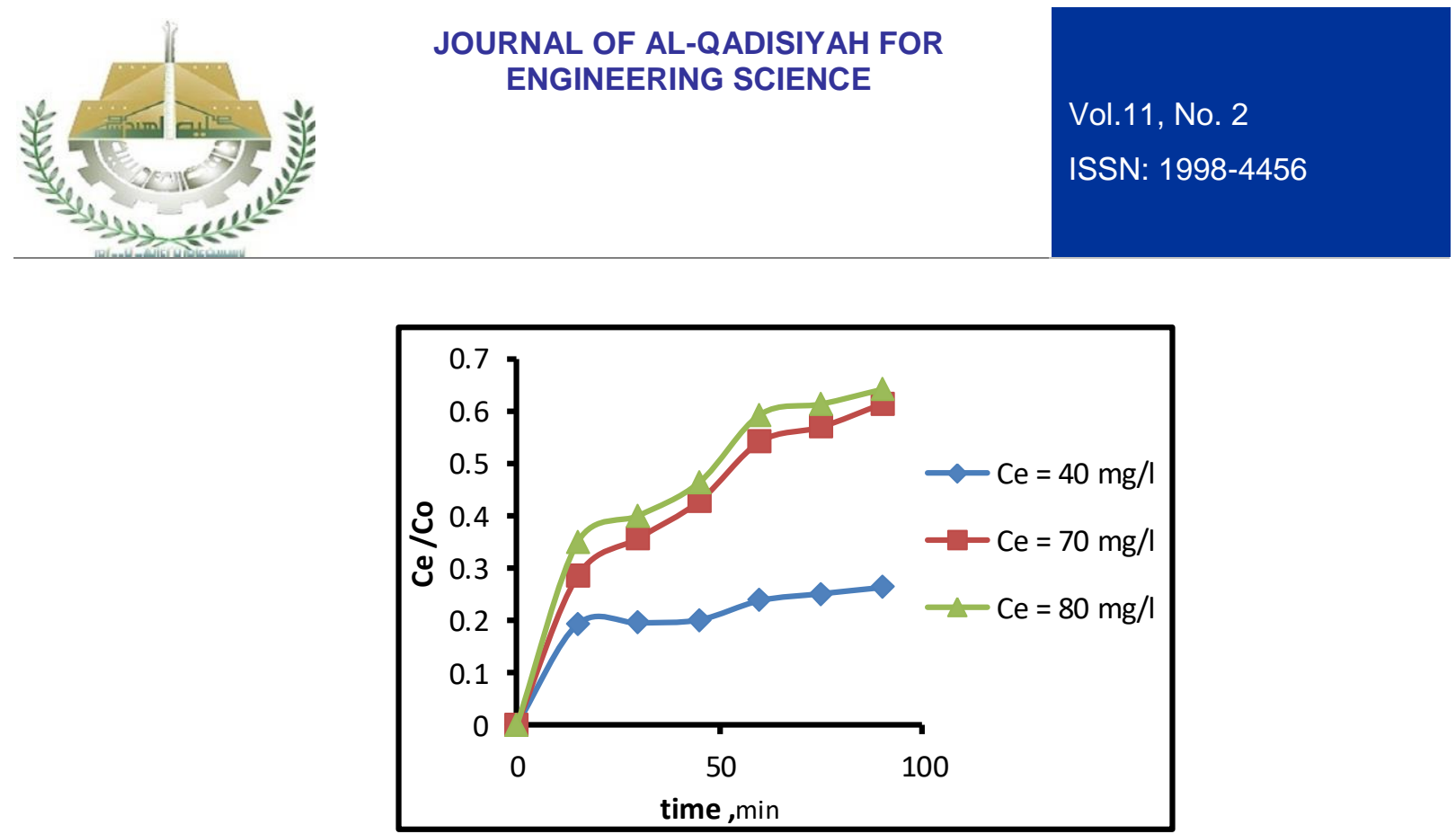

Figure 19. Breakthrough curves for terasil dye adosorption onto conocarpus - after chemically treated, at different initial concentrations, $20^{\circ} \mathrm{C}$, and $\mathrm{pH} 3$.

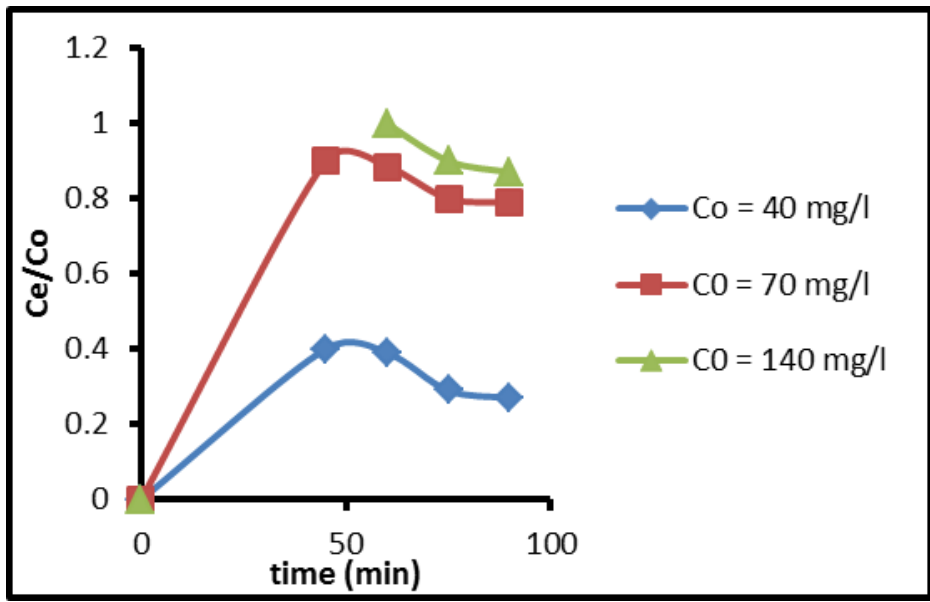

Figure 20. Breakthrough curves for terasil dye adsorption onto conocarpus - without chemically treated, at different initial concentrations, $20^{\circ} \mathrm{C}$, and $\mathrm{pH} 3$.

\section{CONCLUSION}

1. It is found that the breakthrough curves depend on the physiochemical properties of the absorbent material such as the composition of the feeding solution, the operation column, the initial concentration, bed depth, and flow rate.

2. It is observed that when the bed depth of conocarpus - chemically treated ,carbonized conocarpus plant and activated carbon increased, the adsorption process becomes more efficient, Either in case of the use of conocarpus - without chemically treated, when the depth of bed increases the adsorption process decrease

3. when use conocarpus - chemically treated, carbonized conocarpus plant and activated carbon , it is shown that the time needed to reach the breakpoint decreases with the flow rate increasing, but in 


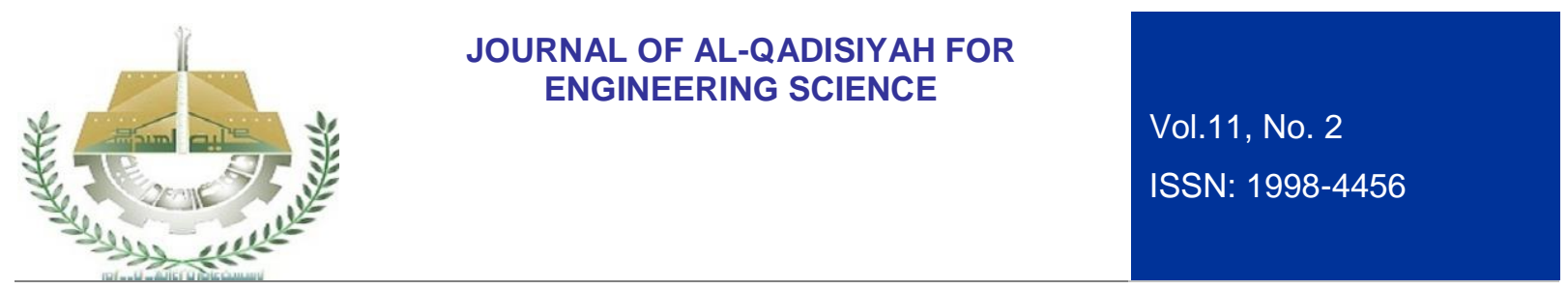

the case of the use of conocarpus - without chemically treated the time we need to reach the break point increases with the increase in flow rate.

4. Note that the time needed to reach the break point decreases with the increase of initial concentration of the terasil blue dye.

\section{REFRENCES}

1. Akdemir EO and Ozer A (2013). Pretreatment of Cheese Whey Effluent Using a Microfiltration Process: A Statistical Design Approach. Ekoloji 22(88): 21-27.

2. Asamudo NU, Daba AS and Ezeronye OU (2005). Bioremediation of textile effluent using Phanerochaetechrysosporium. African Journal of Biotechnology 4: 1548-1553.

3. Aydin S, Güneysu S and Arayici S (2007). Investigation of using adsorbents obtained from sewage sludge with pyrolysis for removal of cod and dye from textile industry wastewater. Ekoloji 16(64): 4348.

4. McKay G (1998). Kinetic models for the sorption of dye from aqueous solution by wood. Process Safety and Environmental Protecttion 76B: 183-191.

5. Han, R., Zou, W., Li, H., Li, Y. and Shi, J., (2006). Copper(II) and lead(II) removal from aqueous solution in fixed-bed columns by manganese oxide coated zeolite, Journal of Hazardous Materials, B137, 934-942.

6. Hussein M (2016). Removal of Methylene Blue Dye from Synthetic Wastewater Using Low Cost Agro-Based Adsorbents M Sc. thesis, College of Engineering, University Putra Malaysia.

7. Korbahti BK (2007). Response surface optimization of electrochemical treatment of textile dye wastewater. Journal of Hazardous Materials 145: 277-286.

8. Kestioglu $\mathrm{K}$ and Yalili M (2006). Treatability of textile industry wastewater with high cod content by chemicalprecipitation and adsorption. Ekoloji 15(59): 27-31.

9. Magdy YH and Daifullah AAM (1998). Adsorption of a basic dye from aqueous solutions onto sugarindustrymud in two modes of operations. Waste Managment 18: 219-226.

10. McKay G, Ramprasad G and Pratapamowli $P$ (1986). Equilibrium studies for the adsorption of dyestuffs from aqueous solution by low-cost materials. Water Air Soil Pollution 29: 273-283

11. Mohan SV and Karthikeyan J (1997). Removal of lignin and tannin colour from aqueous solution by adsorption onto activated charcoal. Environmental Pollution 97: 183-187.

12. Namasivayam C, Muniasamy N, Gayatri K, Rani M and Ranganathan K (1996). Removal of dyes from aqueous solutions by cellulosic waste orange peel. Bioresource Technology 57: 37-43.

13. Ozminci S and Kargi $F$ (2006). Utilization of powdered waste sludge (PWS) for removal of textile dyestuffs from wastewater by adsorption. Journal of Environmental Management 81(3): 307-314

14. Ramadan A, Ghazal R and Jarges K (2005). Preparation of activated carbon from cocusTree residues using modified carbonate and chemical thermal activating, Qatar Journal of Chemistry 18,161-169

15. Senel U, Sur HI, Demirtas M (2012). Investigation of mutagenic effects of some synthetic reactive dyes in textile industry by using umu-test. Ekoloji, 21(85): 49-56.

16. Wang, R.C, Kuo, C.C. and Shyu , C.C., (1997). Adsorption of Phenols onto Granular Activated Carbon in a Liquid.Solid Fluidized Bed , J. Chem. Tech. Biotechnol, 68, 187-194. 